\title{
Diurnal Effects on Satellite Network Performance Measured In Tropical Region
}

\author{
Radhika Prashant Bodhe ${ }^{1}$, Prof. Bharti Singh ${ }^{2}$ \\ I(electronics and telecommunication, K.J Somaiya college of engineering, Vidyavihar Mumbai, India) \\ ${ }^{2}$ (electronics and telecommunication, K.J Somaiya college of engineering, Vidyavihar Mumbai, India)
}

\begin{abstract}
The performance and availability of Ku band satellite Broadband and DTH services are affected by rain fade.. Direct-to-home very Small aperture terminal system operating at frequencies above $10 \mathrm{GHz}$ in tropical climate are subjected to many fade occurrences due to heavy rain. This paper presents diurnal varation on the performance of DTH (Direct to home) broadcasting service for the month of February.
\end{abstract}

Keyword: DTH service, diurnal variation, quality of service, rain attenuation,

\section{Introduction}

In the design of $\mathrm{Ku}$ band satellite links such as direct to home very small aperture terminals (DTH/VSAT) systems, detailed propagation information must be needed to provides better performance, availability, and quality of service [1].These $\mathrm{Ku}$ band services are affected by outages for time-critical transmission such as real-time news and sports broadcasting. The DTH yearly availabilities is of $99.5 \%$ so the corresponding outage of $0.5 \%$ is equivalent to 44 hours per Year. These 44 hours of outage are not usually distributed evenly but are more likely to occur at certain times of the day and are quite often concentrated within a particular season. Such variations will affect customers' services. The probable duration of rain at a given level, effect of weather conditions on the performance of service, what time of the day it is highly affect the service these are the important aspect that will contribute to improve availability of DTH service which leads improve customers satisfaction.[2]

\section{DTH BROADCASTING SERVICES}

DTH network consist of broadcasting center, satellites, encoders, multiplexers, modulators and DTH receivers. A DTH service provider has to lease Ku band transponder from the satellite. The encoder converts the audio, video and data signal into the digital format and the multiplexer mixes these signals. AT the user end, there will be small dish and set top box to decode and viewed numerous channels [3]

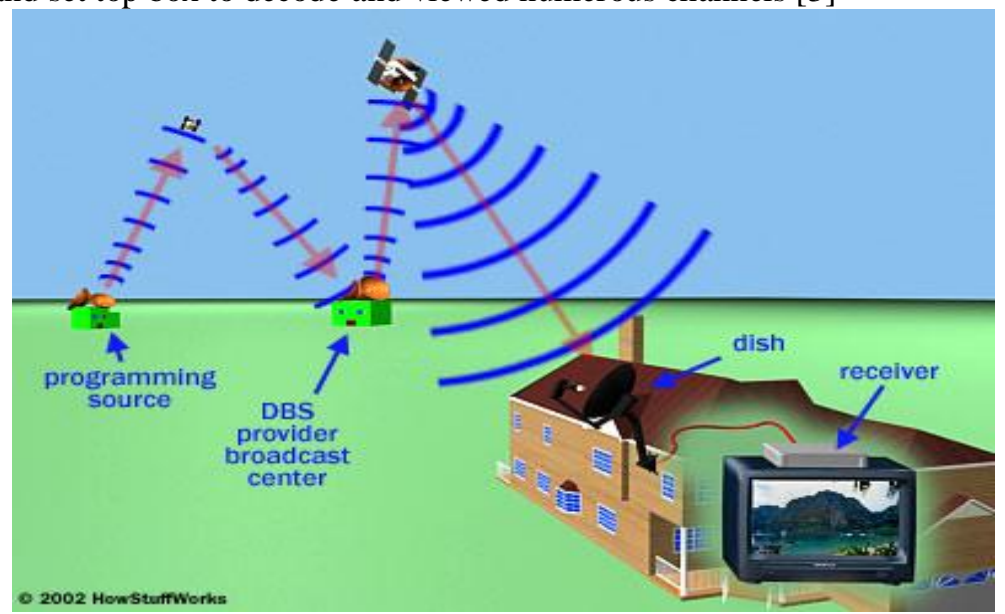

Fig.1 DTH Network

\section{RAIN ATTENUATION AND DIURNAL VARIATIONS}

Rain attenuation is dominant propagation impairment at $\mathrm{Ka}$ and $\mathrm{Ku}$ band frequencies (i.e. radio frequencies above $10 \mathrm{GHz}$ ) and this is even more pronounced in tropic and equatorial region. The raindrops absorb and scatter radio energy, resulting in rain attenuation. The non spherical structure of rain drops can also change the polarization characteristics of signal resulting in rain depolarization. These two factors degrade the reliability and performance of satellite communication link[4][5][6].

Apart from the rain attenuation the DTH service also shows diurnal variation in signal strength.. The signal shows the variation with atmospheric conditions such as humidity, cloud, temperature which is collected 
from Indian Meteorological Department (IMD). Such variation in signal strength affects the performance of the system so understanding of diurnal effect on DTH service is need to be study to improve the availability and performance of DTH broadcasting services.

\section{Experimental Setup}

The main station for the experiment was carried out in Dombivli situated at $19.2184^{\circ} \mathrm{N}, 73.0867^{\circ} \mathrm{E}$ and the elevation angle is $62.5^{\circ}$ above sea level: $19 \mathrm{~m}=62 \mathrm{ft}$ (Dombivli online website) [ 7]. The signal strength variation is recorded for the month of February with a DTH antenna. The DTH antenna is installed over the roof-top. The weather data was collected form AWS (accurate weather station) near Dombivli.

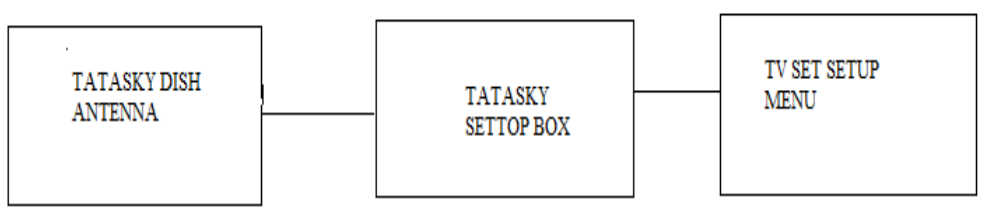

Fig.1 Experimental setup

\section{OBSERVATION AND RESULTS}

The signal strength was recorded for the month of February from morning 8.00 am to $11.00 \mathrm{pm}$ night. Because of wide range of observations it is convenient to show only two days observation in the paper.

TABLE. 1 Observation for $11^{\text {th }}$ February 2013

\begin{tabular}{|c|c|c|c|c|c|c|}
\hline Time & Signal & Humidity & Temp & $\begin{array}{l}\text { Uv } \\
\text { index }\end{array}$ & $\begin{array}{l}\text { Cloud } \\
\text { cover }\end{array}$ & Dew point \\
\hline 8.00am & 201 & $47 \%$ & 25 & 2 & $16 \%$ & 13 \\
\hline 9.00am & 196 & $72 \%$ & 23 & 4 & $33 \%$ & 18 \\
\hline 10.00am & 193 & $53 \%$ & 28 & 6 & $30 \%$ & 17 \\
\hline 11.00am & 193 & $39 \%$ & 32 & 8 & $26 \%$ & 16 \\
\hline 12.00pm & 193 & $31 \%$ & 34 & 8 & $25 \%$ & 15 \\
\hline $1.00 \mathrm{pm}$ & 193 & $39 \%$ & 32 & 8 & $18 \%$ & 17 \\
\hline $2.00 \mathrm{pm}$ & 193 & $33 \%$ & 34 & 6 & $18 \%$ & 17 \\
\hline $3.00 \mathrm{pm}$ & 193 & $39 \%$ & 32 & 4 & $19 \%$ & 17 \\
\hline $4.00 \mathrm{pm}$ & 193 & $36 \%$ & 32 & 2 & $16 \%$ & 16 \\
\hline $5.00 \mathrm{pm}$ & 201 & $38 \%$ & 31 & $\mathbf{0}$ & $15 \%$ & 15 \\
\hline $6.00 \mathrm{pm}$ & 191 & $39 \%$ & 30 & $\mathbf{0}$ & $33 \%$ & 14 \\
\hline 700pm & 201 & $43 \%$ & 28 & $\mathbf{0}$ & $31 \%$ & 15 \\
\hline 8.00pm & 198 & $48 \%$ & 27 & $\mathbf{0}$ & $25 \%$ & 15 \\
\hline $9.00 \mathrm{pm}$ & 196 & $51 \%$ & 26 & $\mathbf{0}$ & $25 \%$ & 15 \\
\hline $10.00 \mathrm{pm}$ & 198 & $54 \%$ & 24 & $\mathbf{0}$ & $24 \%$ & 14 \\
\hline 11.00pm & 198 & $58 \%$ & 23 & $\mathbf{0}$ & $23 \%$ & 14 \\
\hline
\end{tabular}

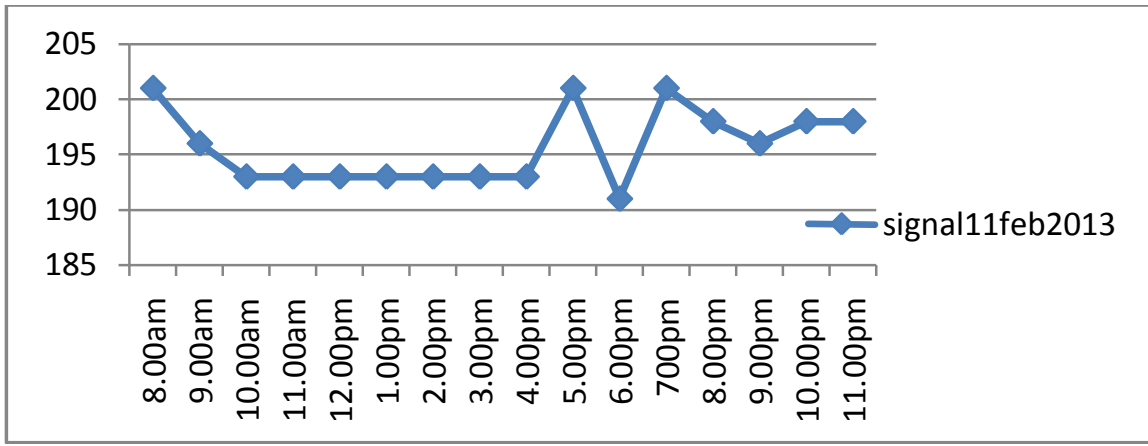

Fig. 2 Signal strength variation w.r.t time 
TABLE. 2 Observation for $21^{\text {st }}$ February 2013

\begin{tabular}{|c|c|c|c|c|c|c|}
\hline Time & Signal & Humidity & Temp & $\begin{array}{l}\text { Uv } \\
\text { index }\end{array}$ & $\begin{array}{l}\text { Cloud } \\
\text { cover }\end{array}$ & Dew point \\
\hline 8.00am & 201 & $47 \%$ & 24 & 2 & $0 \%$ & 12 \\
\hline 9.00am & 201 & $70 \%$ & 19 & 4 & $0 \%$ & 13 \\
\hline 10.00am & 198 & $45 \%$ & 23 & 7 & $0 \%$ & 11 \\
\hline 11.00am & 193 & $31 \%$ & 28 & 9 & $0 \%$ & 9 \\
\hline 12.00pm & 193 & $49 \%$ & 30 & 9 & $14 \%$ & 18 \\
\hline $1.00 \mathrm{pm}$ & 198 & $36 \%$ & 32 & 9 & $12 \%$ & 15 \\
\hline $2.00 \mathrm{pm}$ & 201 & $27 \%$ & 33 & 7 & $10 \%$ & 12 \\
\hline $3.00 \mathrm{pm}$ & 193 & $23 \%$ & 34 & 4 & $8 \%$ & 11 \\
\hline 4.00pm & 201 & $22 \%$ & 34 & 2 & $6 \%$ & 10 \\
\hline $5.00 \mathrm{pm}$ & 201 & $24 \%$ & 32 & $\mathbf{0}$ & $4 \%$ & 9 \\
\hline $6.00 \mathrm{pm}$ & 201 & $26 \%$ & 30 & $\mathbf{0}$ & $2 \%$ & 9 \\
\hline 7.00pm & 201 & $34 \%$ & 27 & $\mathbf{0}$ & $0 \%$ & 10 \\
\hline 8.00pm & 201 & $41 \%$ & 25 & $\mathbf{0}$ & $0 \%$ & 11 \\
\hline $9.00 \mathrm{pm}$ & 201 & $44 \%$ & 25 & $\mathbf{0}$ & $0 \%$ & 12 \\
\hline $10.00 \mathrm{pm}$ & 201 & $46 \%$ & 24 & 0 & $0 \%$ & 12 \\
\hline 11.00pm & 201 & $45 \%$ & 24 & $\mathbf{0}$ & $0 \%$ & 12 \\
\hline
\end{tabular}

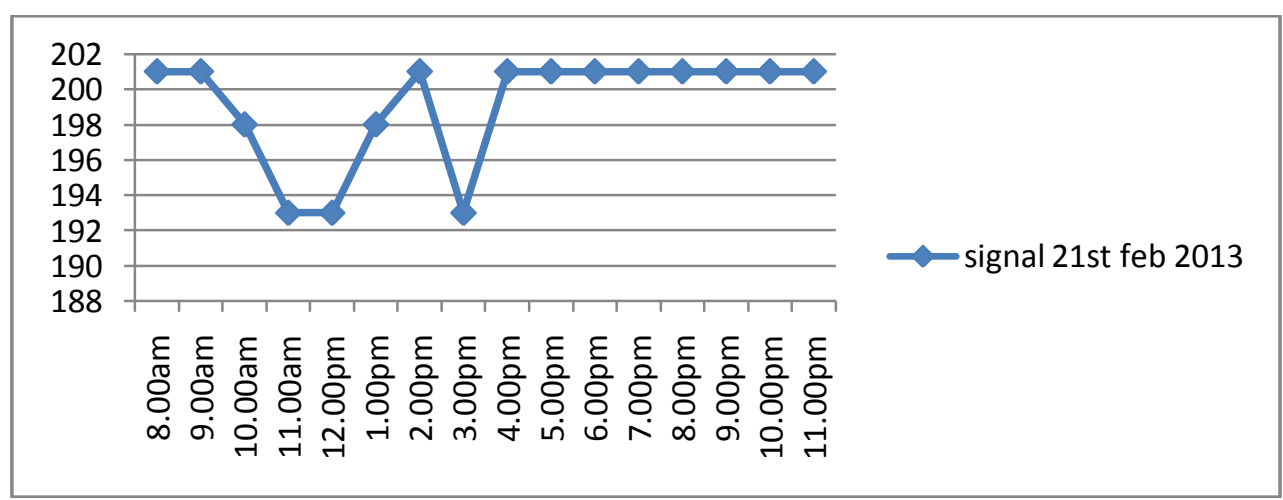

Fig.3 Signal strength variation w.r.t. Time

By observing signal variation for complete month, it was observed that the DTH signal strength varies with Temperature, Humidity, Cloud covers ect. The signal data and Temperature both shows the co-relation. When temperature is quite low in morning or in night the signal strength was good but in afternoon temperature goes to high which drop the signal strength and reduced quality of DTH signal.

Changes in temperature, moisture, and pressure in the atmospheric column cause a change in atmospheric density, which in turn causes variations in the speed of EM waves in both the vertical and horizontal. These changes in speed lead to changes in the propagation direction, or bending, of the waves. The bending of EM waves as they pass through the atmosphere is an example of refraction (see Figure 4). Refraction is always such that the waves turn toward the medium in which they ravel more slowly, as they pass from a faster speed medium into a slower speed medium. This is the case shown in Figure 4, where medium a is the faster speed medium. Refraction causes waves to turn back toward the slower speed medium as they pass from the slower into the faster medium. 


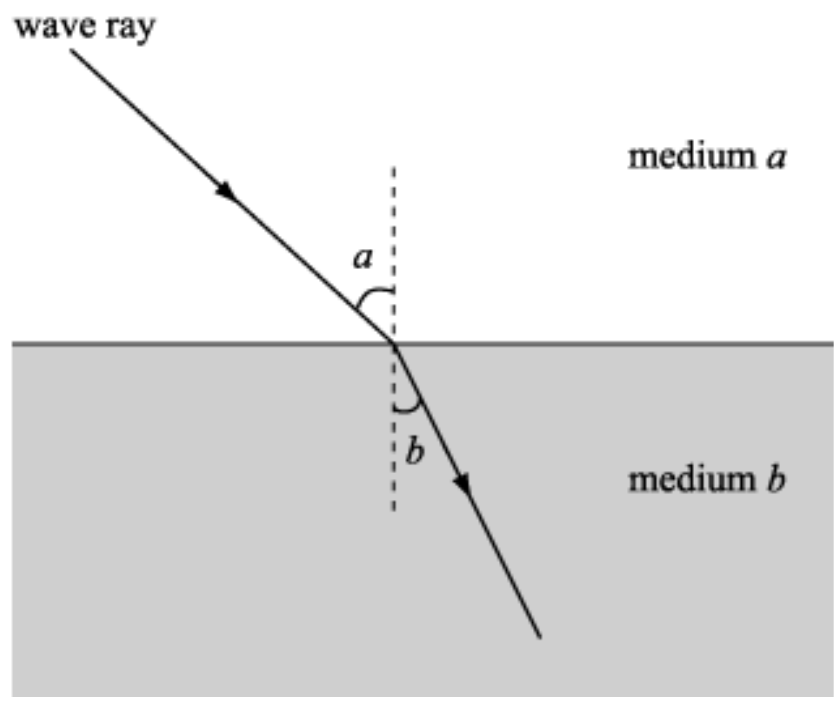

Fig.4 Simple Refraction

As the atmospheric temperature changes the refractivity also changes from the relation shown below and therefore the wave which will going to travel from higher refractivity medium to lower refractivity medium due to change in temperature get affected and attenuated causing reduction in quality of service.

$$
N=\frac{77.6}{T}\left[p+4,810 \frac{e}{T}\right] .
$$

Refractivity $\mathrm{N}$ is related to the temperature in ${ }^{\circ} \mathrm{K}$, to atmospheric pressure $P$ in millibars and to water vapor pressure $e$ in millibars

\section{CONCLUSION AND DISCUSSION}

Performance and availability of $\mathrm{Ku}$ band satellite broadband and DTH service are affected by atmospheric variation. The signal strength shows fluctuation when there is change in temperature, humidity and cloud cover. When temperature is quite low in morning or in night the signal strength was good but in afternoon temperature goes to high which drop atmospheric refractivity causes attenuation and bending of signal and hence reduces the quality of DTH service. Such variations will affect customers' service perception if long and frequent outages are encountered at critical times.

As a communication Engineers it is necessary to study these variation for longer period of time to improve availability of DTH service and that work is in progress.

\section{REFERENCES}

[1], “12 GHz diurnal fade variations in the tropics,” IEE Electron. Lett., vol. 36, no. 9, pp. 891-892, May 2000.

[2] Q.W. Pan, J. E. Allnutt, and F. Haidara, "Seasonal and diurnal rain effect on Ku-band satellite link designs in rainy tropical regions," IEE Electron. Lett., vol. 36, no. 9, pp. 841-842, Apr. 2000.

[3] http://electronics.howstuffworks.com/satellite-tv2.htm

[4] J. E. Allnutt and F. Haidara, "Ku-band diurnal rain fade statistics from three, two-year, earth-space experiments in equatorial Africa," in Proc. URSI Commission F Open Symp. Climatic Parameters in Radiowave Propagation Prediction, Ottawa, Canada, Apr. 27-29, 1998, pp. 159-162.

[5], "Ku-band fade duration data from three, two-year, earth-space experiments in equatorial Africa," Proc. URSI Commission F Open Symp. Climatic Parameters in Radiowave Propagation Prediction, pp. 163-166, Apr. 27-29, 1998.

[6] Q. W. Pan, G. H. Bryant, J. McMahon, J. E. Allnutt, and F. Haidara, "High elevation angle satellite-to-earth 12 GHz propagation measurements in the tropics," Int. J. Satellite Commun., vol. 19, no. 4, pp. 363-384, Aug. 2001.

[7] http://mydombivli.tripod.com 